\title{
¿Es posible planificar un curso de formación docente desde una perspectiva de comunidades de práctica?
}

DOI: $10.46932 / \mathrm{sfjdv2n1-057}$

Received in: November 1st, 2020

Accepted in: December 30th, 2020

\author{
Greici Lenir Cañete Reginatto \\ Doctora en Lingüística Aplicada en UNISINOS - Brasil \\ Profesora en la Facultad de Educación - UDE - Uruguay \\ E-mail: greicicanete@gmail.com
}

\section{RESUMEN}

Este artículo es un recorte de un estudio más amplio y muestra el análisis discursivo desde la cortesía verbal de una investigación realizada con docentes de cursos de formación docente en Brasil, Argentina y Uruguay. En dicho estudio creamos un proyecto piloto, por medio de una investigación colaborativa, al planificar una disciplina internacional en el ambiente Moodle que lograra unificar las asignaturas de las profesoras colaboradoras, reuniendo así sus alumnos virtualmente. Con este análisis pretendemos identificar si es posible constituir una comunidad de práctica en los moldes de Wenger (2001) y Marlangeon (2014), como práctica pedagógica. Para ello, la metodología se basa en Herring (2004) para el enfoque del análisis discursivo de datos escritos virtualmente y en Briz (2012) para el análisis de la (des)cortesía. Los datos extraídos de la interacción generada entre las docentes son el resultado de la negociación entre ellos para la planificación del curso en el ambiente virtual. Se constató que el proyecto no marchaba en virtud de la falta de identificación de las docentes con el mismo, por los roles sociales que asumieron a lo largo del trabajo y las diferencias culturales académicas.

Palabras clave: Disciplina internacional, (Des)Cortesía verbal, Comunidades de práctica.

\section{INTRODUCCIÓN}

El MERCOSUR ha requerido nuevas políticas lingüísticas para la enseñanza de segundas lenguas y una necesidad urgente en mejorar su enseñanza. Para lograrlo se podría favorecer el intercambio cultural y lingüístico, lo que podría ser alcanzado fomentando la construcción de Comunidades de Práctica en ambientes virtuales. Entendemos comunidad de práctica como un grupo de personas bajo un objetivo común que tienen entre sí: compromiso mutuo, trabajo, repertorio, identificación, jerarquía de papeles sociales y afiliaciones (WENGER, 2001).

Además para Wenger, el aprendizaje, tomado desde el punto de vista social, también requiere de otros factores importantes: el significado, la práctica y la identidad. El significado se refiere a que aprendemos mejor si el objeto de estudio se relaciona con nuestra capacidad de experimentar la vida y el mundo en el que vivimos como algo significativo. La práctica emana de las historias sociales en las que nuestra participación es reconocida como competencia. La identidad se trata del cambio que el aprendizaje impacta en nuestro ser, por ende, están las historias personales, el "llegar a ser" en el contexto de nuestras comunidades. (WENGER, 2001:2). 
El "llegar a ser" que hemos querido con este estudio consistía en juntar tres disciplinas curriculares existentes en cada curso de formación de profesores de distintos países en un ambiente virtual, a fin de reunir sus respectivos grupos de estudiantes. Como investigadora suponía que dos o más disciplinas reales llegarían a ser en un ambiente virtual una disciplina que la llamé "Disciplina internacional" con la idea de que hubiese intercambio de conocimiento e interculturalidad. Para ello, los participantes deberían ocupar ciertos roles dentro de la comunidad de práctica, es decir, las docentes colaboradoras las cuales eran las profesoras titulares de las disciplinas curriculares en sus respectivas universidades deberían ocupar el núcleo de la comunidad de práctica, siendo activas y deliberando sobre cómo debería marchar el proyecto, los estudiantes ocuparían un rol en la periferia, así llamado por Wenger (2001), trayendo insumos a la comunidad, alimentándola de conocimientos de mundo buscando puntos de encuentros con el conocimiento académico adquirido por la interacción con los demás. Y finalmente, esta investigadora académica, autora del artículo, ocuparía el rol de observador, quien brinda insumo académico teórico a las docentes de su investigación colaborativa.

Esta investigación busca identificar si es posible constituir una comunidad de práctica en los moldes de Wenger (2001) y Marlangeon (2014), por medio del análisis discursivo desde la cortesía verbal en un estudio realizado con profesores de cursos de formación docente en Brasil, Argentina y Uruguay en el que tuvimos la finalidad de planificar un único curso internacional en el ambiente Moodle unificando las asignaturas de cada docente y reuniendo las clases virtualmente. Con ese propósito la investigación se desarrolló del año 2015 al 2016. En nuestra posible comunidad de práctica estuvimos involucrados siete participantes, siendo una la investigadora, la tutora de la investigación, y cinco docentes colaboradoras.

La idea inicial era que las docentes formasen una comunidad de práctica, al discutir y planificar actividades y metodologías, y que los estudiantes forman una comunidad de aprendizaje, al estudiar y hacer las mismas tareas trabajando en equipos trasnacionales. Sin embargo, no marchó todo bien como lo suponíamos desde el inicio, las trabas en el diálogo entre las docentes involucradas se nos hizo un poco difícil esa tarea, y no llegamos a ser una comunidad de práctica con los estudiantes.(WENGER, 2001).

Este artículo presenta marco teórico sobre internacionalización y regionalización donde se plantea nuestro concepto de educación en casa, además de los objetivos para el MERCOSUR en cuanto a la enseñanza superior y la comunidad de práctica desde el punto de vista de la (des)cortesía, a seguir figuran la metodología, el análisis de datos de los correos electrónicos entre las docentes ${ }^{1}$, y, por último, las consideraciones finales.

\footnotetext{
${ }^{1}$ Se cambiaron los nombres verdaderos de las docentes por nombres ficticios, así como se omitió el nombre de las instituciones. También, se mantuvo la escrita original en los datos escritos por computadora, abreviatura, errores ortográficos, interferencias lingüísticas etc.
} 


\section{1/INTERNACIONALIZACIÓN Y REGIONALIZACIÓN EN CASA}

La internacionalización en la enseñanza es un conjunto de estrategias para lidiar con los fenómenos del mundo globalizado interfiriendo en las prácticas educativas nacionales. Dichas estrategias, generalmente, son propuestas o incluso impuestas a los países por la UNESCO o Banco Mundial entre otros, con el fin de volcar la educación hacia la competitividad del mercado global. En cambio, la regionalización es un proceso paralelo al de la globalización, juntar los países en un bloque establece estrategias para hacerle frente a la globalización y a los problemas que conlleva a los ámbitos económicos, políticos, culturales y a las identidades de los sistemas educativos. (HALL, 20005; FAJARDO, 2007: 67).

Un bloque regional ocupa un marco importante en las políticas lingüísticas de nuestra región, en nuestro caso, el MERCOSUR. Es evidente que, para integrar económicamente, se hacen necesarias acciones para formar una identidad cultural regional, $y$, por lo tanto, entre sus objetivos estratégicos luce el de “promover y fortalecer los programas de movilidad de estudiantes, pasantes, docentes, investigadores, gestores, directores y profesionales" (MERCOSUR, 2011:14). Y, finalmente, anhela la

Organización y fortalecimiento de redes (institucionales y académicas) que faciliten el intercambio de información y de experiencias educativas para asegurar las capacidades nacionales y aportará a la disminución de las asimetrías. (MERCOSUR, 2011: 15).

Entre las estrategias necesarias para ello, tomamos la internacionalización en $\operatorname{casa}^{2}$, por la óptica de Gonçalves (2009) la cual pretende alcanzar las metas de la transfronterización de la enseñanza, pero sin exigencias de movilidad física, o sea, el estudiante, el docente o los currículos dialogan desde su país de origen, gracias a la fluidez de las herramientas tecnológicas, que además, de romper con las barreras de espacio y de tiempo nos cambian nuestras identidades, ahora más desfragmentadas y multifacéticas. (HALL, 2005). Ahora bien, para esta investigación nos posicionamos ideológicamente adaptando el término internacionalización en casa para regionalización en casa, ya que este estudio se pauta en el intento de acercar a tres países vecinos y porque creemos que nos faltaría sumar esos tipos de esfuerzos para así cumplir con algunas de las metas del Sector Educativo del Mercosur.

\subsection{COMUNIDAD DE PRÁCTICA (DES)CORTES}

Según Marlangeon (2014), por medio del lenguaje, las normas de (des)cortesia son el punto central de las interacciones, del trabajo, y de la cooperación mutua de las comunidades, las cuales la autora llama de comunidades de práctica cortés y comunidades de práctica descortés. En las comunidades de habla las personas comparten signos lingüísticos y actitudes que revelan (des)cortesía, construidas en la vida social, pues comparten un modo común del discurso. Dentro de una comunidad de habla, pueden coexistir múltiples

\footnotetext{
2“ Internationalization is interpreted to be the creation of a culture or climate on campus that promotes and supports international/intercultural understanding and focuses on campus-based activities"(SPRING, 2004).
} 
comunidades discursivas, las cuales comparten información especializada, manejan diferentes géneros discursivos escritos y orales referentes a los diversos dominios de la vida social y privada. Por consiguiente, comparten normas de intencionalidad comunicativa y también la actitud dialógica de los textos, habiendo mecanismos de intercomunicación, retroalimentación, género específico y terminología especializada dentro de una comunidad. (MARLANGEON, 2014: 16).

En una comunidad de práctica hay una o más comunidades discursivas, pero no toda comunidad de habla o discursiva se constituye en una comunidad de práctica por las razones que vimos en Wenger (2001). Es decir, que para llamarse una comunidad de práctica, dentro de ella deben haber relaciones y jerarquías favorables, y dentro de esas relaciones, el trabajo en común ocurre por medio de comunidades discursivas. Así siendo en una comunidad de práctica cortés existe el compromiso mutuo, tácito o expreso, la protección recíproca de las imágenes públicas de los miembros formando una noción de empresa, compartiendo repertorio de diversos modos de ser cortés (MARLANGEON, 2014: 13).

Para observar la (des)cortesía en una comunidad se hace necesario observar las relaciones de poder entre los miembros de la comunidad. Desafíos, desacuerdos, negociación y competitividad pueden ser las formas de participación en una comunidad de práctica cuyo repertorio compartido son los modos de producir (des)cortesías, “[ $[. .$.$] palabras, símbolos, gestos, géneros discursivos, acciones y premisas$ involucradas.”(MARLANGEON, 2014: 13). Según ella las relaciones y jerarquías que se forman dentro de la comunidad de práctica son muy importantes, pues la descortesía afecta a los objetivos comunes.

\section{METODOLOGÍA}

Como metodología utilizaremos la investigación colaborativa de Desgagné (2007), Herring (2004) como enfoque de análisis de datos escritos generados virtualmente y de Briz (2012) para el análisis de la cortesía verbal presente en las interacciones escritas de las docentes al planificar los contenidos del curso virtual. Es decir, que los docentes colaboradores no sólo ayudan al investigador a recolectar los datos sino que también son muy importantes sus punto de vista sobre la práctica.

\subsection{DISCURSO MEDIADO POR LA COMPUTADORA Y LA CORTESÍA VERBAL}

El Análisis del Discurso Mediado por la Computadora (ADMC) usa como objeto de análisis variados textos, generalmente escritos, es decir, digitados, tales como los emails, grupos de discusión, chats a tiempo real, etc; cuyas propiedades lingüísticas son cambiantes dependiendo del sistema de mensajería utilizado, además de los contextos sociales y culturales incorporados en las instancias de uso. Los datos aquí son naturales, producidos por los participantes del discurso online para determinados fines. (HERRING, 2004: 10). Ella comprende que las interacciones virtuales pueden generar aprendizaje desde el paradigma social al igual que Wenger(2001), por consiguiente, Herrin (2004) las llama“comunidad de práctica virtual”. La 
autora busca identificar a las comunidades de práctica a través de los comportamientos discursivos virtuales:
a) Estructura: uso de jergas, lenguaje para marcar pertenencia o exclusión del grupo;
b) Significado: Intercambio de conocimiento, negociación de significado (actos de habla);
c) Interacción: reciprocidad, participantes principales;
d) Comportamiento social: solidaridad, administración de conflictos, identidades;
e) Participación: frecuencia regular, actividad autosustentable a lo largo del tiempo.

Sin embargo, el Análisis de Discurso Mediado por la Computadora es un enfoque de investigación muy amplio, por lo que se diferencia de otros análisis del discurso más tradicionales. Y por ello, se necesita de otra(s) metodología(s) de análisis linguiísticos para auxiliar a evidenciar y destacar en los datos las huellas de la existencia o no de una comunidad o bien del aprendizaje social. Para cumplir con la metodología de análisis de datos nos basamos en la (des)cortesía verbal de paradigma sociocultural de Briz (2012: 41). Según él luego de tener la transcripción completa de las interacciones escritas o orales, conviene separarlas en segmentos informativos, actos y subactos, pues dentro de un acto hay otros secundarios, los subactos, habiendo entre ellos una relación de jerarquía, que pueden tener significados y intencionalidades, por medio de modalizadores textuales. (BRIZ, 2012: 61). Tales como:

a) Las exhortaciones pseudoinclusivas (EP) las cuales hacen uso de la referencia inclusiva, son una estrategia de acercamiento, la intención perlocutiva busca crear una solidaridad simbólica borrando la distancia;

b) La atenuación - sirve para prevenir o reparar los daños a la imagen del yo o del tú-yo, la intromisión o invasión de territorio; (BRIZ, 2012),

b.1) La mitigación- La referencia indirecta la cual se usa para mitigar una crítica, “este trabajo no está bien hecho", usa elementos lingüísticos para atenuar y proteger la imagen de ambos evitando conflictos;

b.2) mitigación predicado doxástico (MPD) - sirve para hacer al interlocutor creer en su opinión sin imponerla (creo que, me parece que, pienso que...)

b.3) mitagación- dubitativa- (MD) sirve para poner dudas (no creo que, quizás, tal vez ...) (Briz, 2012:20);

c) La repetición - el oyente repite toda o parte de la preposición emitida por el interlocutor para dar a entender que comparte el mismo punto de vista;

d) La ironía - es la reproducción por la manipulación del valor veritativo de la expresión adoptada (p.20). Tiene un significado contrario a lo referido explícitamente, da un distanciamiento interaccional.

\subsection{LOS PARTICIPANTES DE LA INVESTIGACIÓN³}

a) La investigadora, autora de este artículo, brasileña, naturalizada uruguaya, licenciada en Letras portugués - español, es docente de español y portugués a extranjeros. Magíster y doctora en Lingüística Aplicada, por

${ }^{3}$ Usamos las siglas P, para profesora seguido de la nacionalidad: A (argentina) B( brasileña) U(uruguaya). 
primera vez conduce una investigación colaborativa, también le ayuda su tutora de tesis investigadora y profesora al igual que su co-tutora de universidad extranjera;

b) Alice(PB) profesora colaboradora, es doctora en Lingüística Aplicada y magíster en Letras. Es uruguaya, pero vive en Brasil desde hace mucho tiempo. Desde 1995, es profesora del curso de Letras en las asignaturas de español de la universidad brasileña que participa de este estudio.

c) Laura (PA), tiene larga trayectoria académica y profesional con renombrada formación en el exterior, es doctora en Letras desde 1988. Desde 1982 se dedica a la enseñanza de español en el ámbito universitario.

d) Paula (PU) es coordinadora de estudios de un Instituto de idiomas que tiene profesorado de español, posee amplia formación en profesorado de ELE, antes ha sido también profesora de francés, es magíster en enseñanza de segundas lenguas por una universidad española;

e) Cecilia (PA) es Profesora en Lengua y Literatura Inglesa, Especialista en Docencia Universitaria, Magíster en Procesos Educativos Mediados por Tecnologías, ha recibido distinción por el Diseño e implementación de innovaciones curriculares asociadas a las Tecnologías de la Información y la Comunicación;

f) Verónica (PA) es profesora en Ciencias de la Educación, y Especialista en Docencia Universitaria. Magíster en Psicología del Aprendizaje, actualmente realiza su tesis de doctorado, en Ciencias de la Educación, en el tema Comunidades virtuales de aprendizaje para la educación superior.

\subsection{LOS CONTEXTOS REALES}

- Brasil - la universidad brasileña - es una gran universidad privada del sur de Brasil, su curso de Letras tiene una duración de cuatro años, forma profesores para la enseñanza pública o privada, también para cursos libres y correctores de estilo.

- Argentina - Dos contextos: la universidad argentina que consta con un curso de licenciatura en Letras con tres orientaciones: lingüística, literaturas modernas y lenguas, literaturas clásicas y lengua. En general dura cuatro años y medio, y forma docentes de español, o investigadores en Lingüística. En la segunda etapa de este estudio la profesora colaboradora ha participado con su grupo de un profesorado de inglés en un instituto privado cuya carrera dura cuatro años,

- Uruguay - participa de este estudio un curso de profesorado de español lengua extranjera, la carrera terciaria tiene duración de dos años.

\subsection{LOS CONTEXTOS VIRTUALES}

En este recorte la investigación trascurre en dos etapas, las cuales tuvieron ambientes virtuales distintos: 
a) $1^{\text {a }}$ etapa: grupo cerrado en Facebook - opción escogida por mi tutora y esta autora, porque el Moodle institucional no aceptaba ingresar participantes externos a la universidad;

b) $2^{\text {a }}$ etapa : Experimentando Moodle - en esta etapa una nueva versión de la plataforma educativa aceptaba ingresar participantes extranjeros sin vínculo con nuestra universidad.

\section{ANÁLISIS DE DATOS}

Analizaremos algunas muestras de emails intercambiados entre las docentes colaboradoras de este estudio al negociar la planificación de las actividades.

\subsection{COMPRENDER LAS PAUTAS PARA FORMAR UNA COMUNIDAD DE PRÁCTICA ERA LO FUNDAMENTAL}

$1^{a}$ etapa 2015-Disciplina Argentina/Brasil/Uruguay. Ambiente: grupo cerrado en Facebook $1^{\circ}$ evento- Sabemos planificar en conjunto, pero no lo hacemos.

24 de agosto de 2015, 18:43:

Hola, Laura,

pensé en textos de formación para profesores /que traten de la enseñanza de español como lengua extranjera. A partir de los textos podríamos proponer algunas cuestiones para discutir,/ relacionando los aspectos discutidos con, por ejemplo, alguna entrevista a algún profesor de lengua. [..] La evaluación se haría a partir de la capacidad de los alumnos de relacionar teoría y práctica en sus discusiones. Es apenas una sugerencia, /si se te ocurre otra alternativa, bienvenida sea.

Si preferís, podríamos discutir todo esto por Skype. /Yo tengo libre el jueves, por la tarde, o podríamos hacerlo también el sábado, por la mañana. Si no podés, seguimos discutiéndolo por e-mail.

Un saludo, Alice

Respuesta de Laura:

Hola, Alice:

Muchas gracias por las aclaraciones,/ entonces el Laboratorio se suprime y queda solo la tarea de los dos textos, ¿no es así? Ahora bien: en qué tipo de textos pensás: / literarios, de revistas, diarios, académicos: lectura de un articulo de alguna especialidad? de que extensión? en español? / qué tendrían que hacer con ese texto: objetivo, tareas, con evaluación ¿o no?...

gracias, cariños, Laura 
Como podemos ver en los mails Alice (PB) intenta negociar con Laura(PA) las primeras actividades del ambiente, el Facebook, para que los alumnos interactúen. En el primer acto Alice (PB) busca una acercamiento de currículos, al decir “pensé en un texto para formación de profesores”. Se suponía que la profesora colaboradora argentina hasta este momento dictaría una disciplina de didáctica del español como lengua extranjera para compartir textos. Sin embargo, no fue lo entendido por Laura (PA) al decir en el subacto:”entonces el Laboratorio se suprime y queda solo la tarea de los dos textos, ¿no es asi? El laboratorio mencionado aquí era una disciplina que Laura (PA) había ofertado en el primer cuatrimestre del año, y en el segundo semestre no se dio, entonces fue en ese correo que ella nos hizo saber que no habría una disciplina similar para compartir textos con Alice(PB).

Alice (PB) en los subactos "Es apenas una sugerencia, /si se te ocurre otra alternativa, bienvenida sea. Si preferís, podríamos discutir todo esto por skype. " sigue usando de mitigación de predicado doxástico (MPD), ella aporta sus ideas sin imponerlas al valerse de muchos verbos en tiempo condicional em vários subactos “(...)podríamos proponer algunas cuestiones para discutir,/ (...) serían el tema de la discusión”, también al ofrecer su ayuda, la cooperación desde el punto de vista de Wenger(2001) y Herring(2004). Asimismo, intenta que la salga a la luz una planificación. En respuesta Alice(PA) además de no contar con la disciplina evidencia en su discurso no haber entendido la propuesta, al usar un conector distanciador “Ahora bien:(...)” pero hace uso de la atenuación y la intención perlocutiva al busca crear una solidaridad simbólica, "que tipo de textos pensás.." dándole a entender a su interlocutora que su aporte es muy importante, que su opinión vale más incluyo que la suya misma (de Laura (PA), y así con ello, salvarse la imagen dañada al darnos la noticia de que se suprimía su disciplina llamada Laboratorio.

Aclaramos que por no haber hecho un encuentro para debatir las normas de cooperación, responsabilidad y compromiso de una comunidad de práctica, tampoco, hemos discutido el nivel de participación que se suponía que cada una debería presentar. Eso ya nos marca el rumbo que tomaría esa primera etapa: la escasa colaboración. (DESGAGNÉ, 2007).

Al no haber respuestas ni frutos de discusión sobre textos, mi tutora y yo invitamos a la participante uruguaya Paula (PU) a formar parte de esta etapa, y también para agregar más participantes alumnos ${ }^{4}$, lo que creíamos que sería interesante para formar una comunidad de práctica y aprendizaje también entre los alumnos. (diario de campo investigadora, agosto de 2015).

\section{$2^{\circ}$ evento - Entrar en acuerdo sobre las actividades.}

El 7 de setiembre de 2015, Alice (PB) escribió:

\footnotetext{
${ }^{4}$ Pues teníamos trece alumnos brasileños, y dos alumnas argentinas, con la entrada de Paula(PU) se sumaron más cuatro estudiantes uruguayos. Por motivos de espacio y de recorte de objetivos de estudio, los alumnos y sus interacciones no forman parte de este análisis de datos.
} 


\section{Compañeras,}

Colaborando en la reflexión de lo qué hacer, les dejo una propuesta

TAREA

1) Pienso que podríamos definir la lectura de un texto teórico / que trate de la interacción (del punto de vista Vigotskiano) y el aprendizaje de lenguas extranjeras. /Podríamos hacerlo relacionando ese tema con, por ejemplo: a. el desarrollo de alguna de las destrezas lingüisticas (comprensión lectora, comprensión oral, expresión escrita y expresión oral) o, b. el papel de la interacción alumno/alumno; c. el papel de la interacción alumno/profesor; $d$. el papel de la interacción entre alumno y las TICs. El texto debería ser acompañado de ejercicios de reflexión vinculados con la práctica docente (teoría y práctica relacionadas).(...) Alice

Aquí Alice(PB) toma la iniciativa de proponer ella misma una tarea, aunque usando recursos de mitigación para no parecer demasiado impositiva, al decir "Pienso que podríamos” y al usar usar la MP “(...)/Podríamos hacerlo”. Pese a que sí la vemos como posicionándose en el centro, en el núcleo de la comunidad de práctica, dejando a las demás en la periferia, es decir, Alice (PB) asume, por conocer a la investigadora y representar a la universidad quizás, el deber de tener que poner en marcha ese proyecto de investigación. En cambio las demás docentes, siguen sin entender el propósito, o no saber cómo tomar un papel deliberativo en nuestra comunidad de práctica. (WENGER, 2001).

El 28 setiembre, Paula (PU) escribió:

Muchas gracias Alice:

Estoy de acuerdo con tus sugerencias./ Lo que no me queda claro es si cada una de nosotras proponemos un tema con una evaluación, / o elegimos entre todas el material, tema y tipo de evaluación. Paula

Paula (PU) le contesta a Alice (PB) con una MPD "estoy de acuerdo..." y otra pseudoinclusiva, “nosotras proponemos...", como un pedido de ayuda para la comprensión de las actividades, es decir, demuestra duda en relación a la propuesta “(...)Lo que no me queda claro es si cada una de nosotras proponemos un tema con una evaluación," . Aquí vemos que nos hizo falta una reunión para aclarar y debatir lo que queríamos de una disciplina internacional, como la llamamos, y cuáles son las pautas para ser una comunidad de práctica para crecer conjuntamente.

El 28 de setembro de 2015, Alice (PB) escribió:

Hola compañeras, 
la idea es que podamos escogerlo en conjunto/ para no perder tiempo con posibles materiales que no se adapten a nuestros grupos. Laura, buen congreso y descanso!

Saludos, Alice.

Alice contesta con mitigación pseudoinlusiva: “(...) la idea es que podamos escogerlo en conjunto, buscando llamar a la participación a sus colegas, incluso a Alice (PA) que está en silencio, deseándole “(...) buen congreso." El comportamiento social de Laura (PA) hasta este momento sigue siendo pasivo, de poca frecuencia.

El 29 de setiembre de 2015, 10:23, Paula (PU) escribe:

Estimadas.

Estoy de acuerdo con la selección de los temas / y la forma de evaluar, / así como con las fechas propuestas por Alice. De todas formas pongo a consideración unos materiales sobre desarrollo de destrezas en el aula ELE, /que, creo que se alinea con lo propuesto.

Si les parece podríamos dar inicio al sitio / y no demorarnos más. Por mi parte les aviso/ que, entre el 5 y el 13 de octubre estaré de viaje con escaso acceso a Internet.

Cariños. Paula

[no adjuntó ningún archivo]

El 29 de setiembre Greici escribe:

Empecemos esta semana, / animen a sus estudiantes! Buen trabajo a todas nosotras. Greici

Paula (PU) sigue con mitigaciones contesta a Greici con copia a todas

El 29/09/2015 16:50, Paula escribió:

¡Genial!!!! Alice: Tú subís el material / y luego apoyo con el mío. ¿Estamos todas de acuerdo con las fechas fijadas para los plazos? Paula

El 29 de septiembre de 2015, Alice contestó:

Bárbaro, Paula. Hoy llego a casa tarde de la noche. Hasta mañana los cuelgo. Saludos!

En esta secuencia de correos las docentes colaboradores intentan negociar los textos que conformarán una secuencia de actividades para los alumnos en el grupo del Facebook, sin embargo hay una falla. Paula (PU) muestra acuerdo con la propuesta de Alice (PB), al decir “ (...)De todas formas pongo a consideración unos materiales sobre desarrollo de destrezas en el aula ELE, /que, creo que se alinea con lo propuesto." 
Usa conectores distanciadores, de todas formas, o sea, está de acuerdo con Alice(PB), pero quiere agregar algo más, para mitigar su participación. No obstante, no sabremos si por descuido o porque pretendía hacerlo después Paula (PU) no adjunta archivos, serían sus textos, tampoco los puso en la carpeta compartida que teníamos en Google drive. Los textos que se hallan allí, son: Baygorria (2013) sobre la corrección del error y el feedback, agregado por Alice (PB) el 30/09/2015, otro de Santamaría y Araneda (2008) sobre espacios interactivos de comunicación y la construcción de identidades, y, por fin, el de Ruescas (2010) sobre la interacción, conciencia y desarrollo de la autonomía en clase, todos añadidos por Alice (PB). O sea, que Paula(PU) no ha cumplido su tarea de subir textos para intercambiar, pese a contestar a la investigadora, la cual siempre usa exhortaciones pseudoinclusivas "buen trabajo a todas nosotras" (Greici) para con ello intentar crear la identificación con el proyecto. Entonces Paula(PU) nos dice “¡Genial!!!! Alice: Tú subís el material / y luego apoyo con el mío. ” Hubo aquí una preocupación en prevenir daños a su imagen, atenuación e incluso valoración por el trabajo de las demás, pero no hubo su aporte. Tuvimos en esta secuencia buena negociación de tareas y participación, pero que no se concretaron en el trabajo de la docente colaboradora uruguaya. Nos falta aquí un poco del compromiso mutuo y de responsabilidad en Wenger(2001). Laura (PA) parece entender que los textos que ya nos había enviado por mail de su disciplina del cuatrimestre anterior ya eran suficientes, y no comprende que debería participar de esta discusión.

El 4 de octubre de 2015, Alice escribió:

Buenas noches, compañeras,

espero que hayan tenido un buen final de semana. / Como les había comentado en el mail que les mandé el jueves pasado (está abajo de este), subí al Google drive 6 textos para que pudiésemos definir cuál seriía aquel que los alumnos deberían leer, reflexionar y discutir con los compañeros (ver propuesta de trabajo mail del 27 de septiembre). Entretanto, como aún no se ha definido, / resalto la necesidad de que lo hagamos lo más pronto posible para que podamos proponer las preguntas que resultarán en la actividad de interacción.

Observé que Paula subió a Facebook dos textos de sitios de la red. Serían material complementario?

Alice (PB) usa atenuación al comienzo de este correo, pero luego les recuerda el mail anterior” Como les había comentado” y sobre los textos “(...)subi al google drive 6 textos para que pudiésemos definir”, o sea, les recuerda, pero intenta no imponer su voluntad. En cambio, alerta sobre los plazos, pues por cuestiones del calendario académico brasileño su disciplina real estaría por finalizar, y ella perdería el control de que sus alumnos hagan las actividades, o bien, porque a ellos ya no les sería interesante participar, 
una vez que estuviesen finalizado su semestre. Por eso ella usa de MPD “(...)resalto la necesidad de que lo hagamos lo más pronto posible” Y al final, usa de MD al preguntar si los materiales colgados por Paula (PU) “(...)serían material complementario? Hemos observado en el grupo del Facebook, que se trataban de materiales sobre el español en el mundo, no había una idea de alineación o bien alguna discusión anterior entre las docentes colaboradoras si servirían de algo para la secuencia de actividades que se deseaba llevar a cabo. En suma, fallamos otra vez con las premisas de la comunidad de práctica, la cortesía mostrada aquí por Alice (PB) demuestra que no quiere herir las imágenes de las demás, pero no hubo negociación entre ambas. Su comportamiento social de administradora de conflictos se evidencia en este fragmento.

El 8 de octubre de 2015, Alice (PB) escribió:

\section{Compañeras,}

Mañana por la mañana pienso enviarles un mail a mis alumnos con las orientaciones que siguen abajo. ACTIVIDAD 1

Plazo de realización: 12 a 26 de octubre. Entra al grupo de Facebook "Disciplina internacional Brasil/Argentina/Uruguay” y responde a las preguntas que se han compartido.

Comparte tus impresiones/opiniones/experiencias definiendo claramente a qué pregunta haces referencia. Intercambia tus opiniones con tus compañeros, especialmente los de Argentina y Uruguay.

ACTIVIDAD 2

Plazo de realización: 26 de octubre a 2 de noviembre

Lee el texto "La corrección del error y el feedback en la clase de lengua extranjera. Un análisis desde los estudios de la afectividad." de autoría de Stella Maris Baygorria.

Alice (PB) intenta con ese “(...)pienso en enviarles... ” intenta no imponer su voluntad, compartiendo con sus compañeras su decisión de actividad, y de hecho, según mis observaciones del contexto virtual, no las colgó en el muro del grupo, al no recibir una respuesta concreta. (diario de campo, investigadora 10/2015). Por lo contrario, las respuestas de sus compañeras fueran las que siguen abajo:

El 21 de octubre de 2015, 20:31, Laura (PA) escribió:

Hola, chicas:

he leído lo que antecede / y es muy buena la propuesta de trabajo. Este semestre, como les había comentado, dicto Literatura española I (Medieval). Propuse que xxx y xxxx colaboraran, ya que hicieron conmigo en el $1^{\circ}$ cuatrimestre el Seminario de Introducción a la Investigación con temas semejantes a los propuestos. ¿Cómo ayudo y qué hago, entonces? Cariños 
En esta conversación Laura (PA) sigue con su comportamiento social de una identidad de quien está lejos del objeto en discusión: las negociaciones de las actividades. Ella no se ha identificado aún con él, y , por lo tanto, aún no entra en el núcleo de la comunidad de práctica. Asimismo, intenta proteger su imagen al mostrarse voluntariosa “¿Cómo ayudo y qué hago, entonces? Cariños”.

Laura (PA) sólo alcanzará otro nivel de comprensión al final de la $1^{\mathrm{a}}$ etapa cuando nos pide subir un Power point con preguntas de auto evaluación a los estudiantes. Puede que no haya sido lo más recomendado para un muro de Facebook, sin embargo, hay que señalar un cambio de identidad, fruto de una reunión por Skype que tuvimos ella y yo (la investigadora), en la que ella pudo evacuar sus dudas sobre mi proyecto. Nuestra conversación duró casi una hora, desde entonces, ella empieza a comprender la propuesta. (diario de campo, investigadora 11/2015).

El 21 de octubro, Paula (PU) escribió:

Hola Alice

Espero que estés bien. Te paso más abajo mi propuesta de trabajo. [...]

Si estás de acuerdo, lo subo y etiqueto a los alumnos de Brasil.

Cariños. Paula

\section{TRABAJO PARA EL GRUPO DE FB}

Pensemos que este grupo es un foro para discutir sobre un tema yacente en la enseñanza de segundas lenguas. El objetivo principal de esta propuesta es que, mediante la realización de un debate en este mismo foro, cada participante reflexione sobre si es posible que los adultos aprendamos a hablar una lengua extranjera sin que hayamos estudiado de manera explícita la gramática de la misma. Chomsky argumentaba que sí era posible. Según el autor, lo que nos permitía aprender una lengua era el contacto rico y variado con hablantes de ese idioma. (negrita usado por ella)

Paula (PU) atenúa al iniciar el mensaje “(...) Espero que estés bien” y luego, plantea usando una oración condicional "Si estás de acuerdo, lo subo y etiqueto a los alumnos de Brasil. Cariños”. Alice y Laura(PA) no le contestaron y ella me preguntó a mí que me parecía la actividad, yo le dije que bien, pero que tendría que verlo con las demás colaboradoras. (Diario de campo investigadora, 10/2015).

$3^{\text {o }}$ evento - Lejos de lo acordado, lejos de cumplir una secuencia de actividades.

El 21 de octubre, Alice (PB) escribió: 


\section{Hola, Paula}

estoy en clase y los chicos están trabajando en los comentarios del Facebook. Leí junto con ellos lo que subiste al grupo / y lo propuesto ahora se aleja un poco de lo que habíamos acordado inicialmente, por lo menos en términos teóricos. / Entonces, pensé que el texto que estaba reservado para que leyesen en la segunda etapa de la actividad (eso iba a ser para más adelante, después del 26 de octubre) y / que tenía relación con las preguntas iniciales, lo olvidamos y nos quedamos centrados en Chomsky y Canale. Me parece mejor.

Copio en este texto a las compañeras para que todas acompañen la tarea y cualquier cosa volvemos a conversar. Besos, Alice

Como podemos ver en los correos que anteceden Paula (PU) a tomado su decisión y subido la actividad sin el aval de las demás colaboradoras, como yo le había planteado, pues siempre se intentó de que el proyecto fuera algo negociado entre las docentes colaboradoras. Resulta que el planteamiento teórico de Paula(PU) iba por otra línea que la brasileña, como hemos podido notar en todos los textos escogidos por Alice (PB) iban alineados con el interaccionismo social como abordaje de enseñanza de lenguas, y esa diferencia cultural de elección de temas y referentes teóricos, cambió totalmente el rumbo de las actividades en nuestro grupo de Facebook. En el subacto Alice (PB) manifiesta su acuerdo a la nueva situación con atenuación, buscando reparar daños a la imagen de Paula (PU), “(...) lo olvidamos y nos quedamos centrados en Chomsky y Canale." Y termina el mensaje con mucha cortesía “(...) cualquier cosa volvemos a conversar." Aunque en realidad, solo una de sus alumnas de Alice (PB) hizo esta tarea, pues los demás no la entendieron, como nos dice la propia docente. Habría que poner en pauta no sólo cómo formar una comunidad de práctica, sino que también cómo negociar y trabajar juntos el tema de la interculturalidad académica. Al final esta etapa sólo tuvo una actividad que fue un "rompehielos" propuesto por Alice (PB) en el que los estudiantes tenían que contestar a una serie de preguntas sobre el aprendizaje de lenguas desde la perspectiva del alumno, basándose en sus propias experiencias. En muchos casos terminó con muchas respuestas con escuetos sí o no. Pero fue la única oportunidad en la que los estudiantes trabajaron y expusieron un poco de sus identidades en línea.

\subsection{QUIÉN ESTUVO UNA VEZ SIGUE QUERIENDO PARTICIPAR}

$2^{\mathbf{a}}$ etapa - El ambiente virtual es el experimentando Moodle de nuestra universidad, la argentina y, luego, con un profesorado de Inglés de un Instituto privado terciario.

\section{$4^{0}$ evento- Cambiamos de equipo y volvemos a empezar.}

En esta etapa, intentamos arreglar los errores de la anterior, partiendo de la premisa que es de los errores que se aprende. Primeramente, Laura (PA) nos sugirió la participación de la responsable por el 
Departamento de Español Lengua Extranjera para el lado argentino, así que al fin contamos con una docente colaboradora más experimentada en TICs, y su tutora, muy conocedora del tema, y que ya desde los primeros contactos quisieron participar del proyecto. Aún tratamos con la misma universidad, sólo habíamos cambiado el equipo de colaboradoras. La primera corrección, fue fijar reuniones periódicas por Skype para debatir no sólo las actividades en sí, sino que también pautas de qué es una comunidad de práctica, y qué queríamos lograr con ello. (Acta de reunión, 01/07/2016). Luego empezó el intercambio de correos electrónicos. Trascurría todo muy bien, hasta que surge una situación incómoda que tiene que ver con la $1^{\text {a }}$ etapa de este proyecto.

El 16 de agosto de 2016 Verónica escribió:

Estimada Greici, /¿cuándo podríamos tener una breve y rápida conversación por Skype, / nosotras dos? quiero consultarte algunas dudas. Nada serio. Atte.

Pese a la atenuación con que encabeza el mensaje, el tipo de conversación a solas, con la EP, “ ¿ ¿...) nosotras dos?, aunque no era "Nada serio." me dejó un poco de inquietud de que algo no marcharía bien, como lo veremos más adelante.

\section{$5^{\circ}$ evento- Negociación de las actividades pese a las nuevas condiciones}

El 12 de septiembre de 2016, Alice (PB) escribió:

Estimadas compañeras,

Las dos asignaturas tienen en común la observación y el desarrollo de proyectos. / Podríamos intentar que los dos grupos discutieran sobre lo que han observado y, / a partir de la discusión, que pudiesen pensar proyectos de enseñanza. Eso involucraría lectura, discusión, búsqueda de material, justificación de sus elecciones... / Es importante decirles que en mi grupo los alumnos elaboran los proyectos que van a aplicar en 2017/1, en la clase de práctica docente./

Como no tengo idea de los plazos que tienen ustedes en Argentina para el desarrollo de las actividades, / sugiero que esto se pueda hacer entre el 21/09 y el 16/11. ¿ ¿Qué les parece?

[...] ¿Qué piensan? / Siéntanse a gusto para sugerir otra propuesta si creen que será más adecuado. Saludos a todas, Alice

En este correo Alice (PB) usa de MPD, comparte su planificación haciéndolo parecer una sugerencia, con recursos pseudoinclusivos, los verbos en condicionales siempre conjugados en el pronombre sujeto <nosotras>: "Podríamos intentar que los dos grupos discutieran sobre lo que han observado y, a partir de la discusión, que pudiesen pensar proyectos de enseñanza. Eso involucraría lectura, discusión, búsqueda 
de material,..." y deberíamos tener la propuesta un poco más concreta." También se hace evidente que otro desafío en este proyecto de reunir las disciplinas y estudiantes, es la diferencia de tiempos en lo que concierne a las estructuras y calendarios académicos y a la falta de conocimiento que tenemos entre nosotros, cuando Alice menciona:“(...)Como no tengo idea de los plazos que tienen ustedes en Mendoza para el desarrollo de las actividades, sugiero que esto se pueda hacer entre el 21/09 y el 16/11."

El 13 de septiembre, Cecilia le escribe a Greici por medio de chat del Facebook:

Greici te escribo porque lamentablemente no voy a poder seguir participando del proyecto. / Como ya te había comentado tengo un familiar enfermo y la situación ahora se ha agravado. / Realmente no dispongo del tiempo en este momento. / Te pido disculpas / y te agradezco tu generosidad. / Espero puedas seguir adelante con Verónica. Te envío un saludo cordial.

El 14 de septiembre de 2016, Verónica le escribe a Greici:

Greici: Gracias por tu atención.

Mi inquietud simplemente pasa por aclararme en el marco de qué acciones llevamos a cabo este intercambio. / Entiendo, y desde ya apoyo totalmente, que nuestros intercambios y contactos están exclusivamente relacionados con dar lugar a un trabajo de campo que pertenece a tu tesis. Por favor corregime si no estoy en lo cierto. Todo esto los pregunto / porque la coordinadora, o la profesora que desde la UNCuyo trabajó para la vinculación y concreción del proyecto de intercambio, me reclamó su participación. / Yo he entendido que esta relación de trabajo en el marco de tu tesis es el resultado de haber entablado la vinculación entre las dos universidades, pero que no forma parte de las acciones del proyecto original. Si vos tenés alguna explicación extra que yo debiera saber te pido la conversemos. Te dejo mi saludo.

Como vemos la docente colaboradora me expone una situación complicada, el comportamiento social aquí es el de administrar un nuevo conflicto, la docente colaboradora de la etapa anterior, Laura (PA), reivindica su participación en mi investigación, porque ya preexistía un convenio de intercambio presenciales entre nuestras universidades, sin embargo, mi investigación de tesis sí justificaba su relevancia al hecho de preexistir un vínculo entre universidades, pero mi tesis es independiente a ello legalmente. Además al enviarnos su diario de campo con un email de autoevaluación Laura (PA), menciona su participación limitada debido a qué no era fácil comprender mi propuesta y la alfabetización digital era muy distinta entre las docentes, incluso me recomendaba: “(...)Seria muy positivo que Verónica participara en el marco del Departamento de Letras; la experiencia de Greicy es aprender y ensenar una lengua, en este caso, ELE, eso es propio del Depto de Letras." el departamento de ELE para seguir. (email Laura PA, 25/01/2015).

Sintiéndose en una situación molesta la docente colaboradora Verónica me pide aclaraciones “(...) en el marco de qué acciones llevamos a cabo este intercambio." Y atenúa para no dañarme la imagen "Si 
vos tenés alguna explicación extra que yo debiera saber te pido la conversemos”, o sea, extra, aún no comentada o explícita, aquí se rompe un poco la confianza y la pertenencia de grupo en cuanto comunidad de práctica virtual. Eso tuvo consecuencias que cambiaron la dirección que llevaba nuestro trabajo. Se pudo aclarar, pero el daño fue irreversible para seguir con lo propuesto inicialmente. Y lo interesante es que podemos leer que un día antes Cecilia (PA) me escribe por chat que no puede seguir ayudándome, ella se vale de mucha atenuación, se excusa muchísimo e intenta salvarse la imagen “(...)Te pido disculpas y te agradezco tu generosidad. Espero puedas seguir adelante con Verónica”.

El 19 de septiembre Cecilia le escribe a Greici por Facebook:

Hola Greici. Estuve hablando con Verónica / y para que no se pierda la posibilidad de articulación / si querés te ofrezco un espacio de Prácticas que tengo en otra institución de nivel terciario. No es la Universidad pero se trabaja bien. / Si te interesa subo el programa al Google Drive. Cariños. Cecilia

Al seguir intentando reparar el malentendido, quizás por un comportamiento social de solidaridad a mí, Cecilia me convence de que puede seguir desde que sea con un Instituto privado en el que trabaja con un profesorado. Busca valorarlo al decir “(...) No es la Universidad pero se trabaja bien.” Y me deja cómoda para decidirlo, al mismo tiempo, que se muestra voluntariosa y sin más vueltas "Si te interesa subo el programa al Google Drive”. Esos recursos me hicieron aceptar la idea. Además estaban las exigencias de la academia, pues debería seguir poniendo en marcha el proyecto como fuera.

El 20 de septiembre de 2016, Greici escribió:

Estimadas Alice y Cecilia,

Primero quisiera comunicarle a Alice que de ahora en delante forma parte del trabajo la disciplina Práctica Profesional IV cuyo Plan de curso se encuentra en la carpeta. Creo que Cecilia podrá explicar mejor de qué se trata y pueden ustedes empezar a negociar sobre las lecturas y actividades. En breve les enviaré formulario para llenar con datos que nos interesan para abrir el Moodle. Muchas gracias y para cualquier consulta me escriban. Greici.

En este correo formalizo el cambio a la docente colaboradora brasileña, pues de ahora en delante deberá tratar de la disciplina del profesorado de inglés en cuestión. De todos modos, busca a través de la interacción darle el papel principal a ellas, Herring(2004), en especial a Cecilia(PA) al decirles "Creo que Cecilia podrá explicar mejor de qué se trata y pueden ustedes empezar a negociar(...)” Luego, Alice (PB) sigue manteniendo su liderazgo en las negociaciones, sin embargo, pese a que los programas analíticos de las disciplinas y las lecturas estuvieran en Google Drive, aún así marcha lento el tema de ingresar a los 
alumnos y docentes en el Experimentando Moodle. Eso deja que se enfrié un poco la negociación sobre las actividades, véase, abajo la cantidad de tiempo trascurrido.

El 12 de octubre de 2016, Cecilia escribió:

Hola Alice :

Sí lamentablemente queda muy poco tiempo. Hoy me dí cuenta que de esas cuatro clases, los alumnos tendrán tres por encontrarme afectada a otra actividad en una de esas clases.

Veo también que tus alumnos continúan con la práctica en 2017, mientras que los míos ya están en el último año y no vuelven a tener esta materia .

Creo que el trabajo debería ser virtual, y estoy de acuerdo con la primera propuesta de que elaboren un proyecto de enseñanza .

De todas maneras si se encuentran trabajando en este proyecto, podrían comenzar este año y concluirlo a principios del año que viene. Habría que ver en mi caso en que contexto lo aplicarían .También les pregunto si habría alguna posibilidad de darles un certificado de participación a los alumnos para motivarlos un poquito a esta altura del año.

Saludos, Cecilia

PD: Si querés nos seguimos comunicando por este medio hasta poder acordar la reunión virtual .

El 12 de octubre de 2016, Verónica (PA) escribió:

Cecilia y Alice: buenas noches.

Creo que a pesar de que los grupos llevan procesos y tiempos distintos podemos hallar algo en común sin importar las clases presenciales que quedan por delante.

Considero que la primer propuesta de Alice es la más factible porque si bien los alumnos de Cecilia ya salieron de la escuela han tenido un buen proceso y tiempo de observación entonces podrían compartir problemas prácticos de distintos niveles.

El primer paso podría ser debatir sobre esos problemas observados, lo cual implica un proceso de identificación y definición de problemas educativos sobre la enseñanza.

El segundo paso podría ser poner en común algunos de ellos en base a las diferencias contextuales y culturales, considerando incluso la intervención de las políticas educativas específicas de cada país El tercer punto la producción de proyectos de enseñanza que refieran a alguna de las problemáticas debatidas.

Espero aportar a la organización del trabajo de los alumnos.

Un abrazo a todas. Verónica. 
En esta secuencia de emails Cecilia plantea el problema de sus tiempos presenciales de su disciplina en curso y los tiempos de los alumnos en respecto a su formación. Ella atenúa como si se le hubiera olvidado/pasado ese hecho “(...)Hoy me dí cuenta que de esas cuatro clases...” Verónica le aclara en su respuesta que “(...) podemos hallar algo en común sin importar las clases presenciales” y que luego de debatir los problemas observados, ellos podrían producir un proyecto que tenga que ver con algún punto de la observación, como que buscándole una alternativa a lo observado. Verónica usa de MPD para darnos sin imponer su opinión, lo mismo al despedirse “(...) Espero aportar a la organización del trabajo de los alumnos". Y, al fin, es ella Verónica (PA) quién publica la entrada en el único foro de Experimentando Moodle, organizando las ideas que anteceden en una consigna de tarea de foro. Los alumnos no contestaron al foro, por problemas técnicos, los argentinos perdieron su acceso al ambiente, y no hubo forma de reparar con la ayuda de nuestro soporte técnico. Al ser difícil hacerlo, se desmotivaron, y obviamente, no salieron los certificados de participación como pedidos por Cecilia. Aquí el comportamiento social de Verónica fue el de la solidaridad, y fue la participante principal al intentar terminar las discusiones con una tarea concreta.

\section{CONSIDERACIONES FINALES}

Como pudimos ver, buscar juntar disciplinas, estudiantes y docentes no es sencillo. Pasa primero por un buen diálogo entre las docentes. En los datos vemos que en la primera etapa hubo muchas faltas de respuestas a lo propuesto por ellas, ralentizando las negociaciones y desmotivando a todas nosotras. O sea, se trató de una supuesta cooperación mutua, pero con falta de compromiso real. (WENGER, 2001). Eso se explica por la participación no autosustentable, y fallas en el significado en lo que respecta a la solidaridad simbólica y negociación. (HERRING, 2004). Los papeles sociales también han sido muy distintos entre las participantes: la investigadora estuvo en el centro de la comunidad, Alice(PB) y Paula(PU) intentaban ocupar el protagonismo. En cambio, Laura (PA) estaba al margen, en la periferia sin entender la propuesta, pidiendo ayuda en algunos momentos, sin éxito, o bien excusando su falta de participación.

Por otro lado, en la segunda etapa pocas veces han faltado respuestas inmediatas, y la comunidad discursiva dentro de la de práctica ha sido de mucha cortesía, Marlangeon (2014), sin embargo, a la hora de concretar las actividades, no se ponían en marcha al momento. Además, se vio todo casi arruinado, por el reclamo de protagonismo de la docente de la etapa anterior Laura (PA).

Los papeles sociales, en el sentido de autorizar o no autorizar el protagonismo del otro han sido evidentes en las interacciones, poner al otro a la periferia al no contestar prontamente su consulta o al no autorizar la consigna de las actividades. Sí, es cierto que había siempre mucha concordancia con lo propuesto por el otro, pero el interlocutor necesitaba más que la cortesía del "estar de acuerdo", necesitaba el permiso final para la publicación de las consignas y la acción y sumado a todo eso encima los problemas técnicos en 
la segunda etapa. Fueron factores que condicionaron nuestro fracaso al constituir una comunidad de practica virtual y la anhelada muestra de posibilidad de regionalización en casa. Sin embargo, hemos tenido éxito en conocer nuestras fallas y el camino que queda por recurrir por la integración cultural y académica. Necesitamos más que docentes de lenguas, necesitamos docentes con una identidad regional, que al conocer las bases teóricas que sostienen la enseñanza de lenguas de los países vecinos, con el conocimiento mutuo, puedan con ello crecer en su labor crítico hacia un aprendizaje colaborativo. 


\section{REFERENCIAS BIBLIOGRÁFICAS}

Briz, Antonio. La (no)atenuación y la descortesía, lo lingüístico y lo social ¿son parejas? In: MORALES, Julio Escamilla, VEGA, Grandfield Henry. Miradas multidisciplinares a los fenómenos de cortesía y descortesía en el mundo hispánico. Estocolmo: Universidad del Atlántico/Universidad de Estocolmo/EDICE, 2012. p. $33-75$.

Desgagné, Serge. O conceito de pesquisa colaborativa: a idéia de uma aproximação entre pesquisadores universitários e professores práticos. Revista Educação em Questão, Natal, v. 29, n. 15, p. 7-35, maio/ago. 2007. Disponível em: <http://www.revistaeduquestao.educ.ufrn.br/pdfs/v29n15.pdf> Acesso em: 28 fev. 2016.

Gonzalez, Carina Soledad. Redes sociales en el aula y su utilización en el contexto universitário. Actas del Congreso Internacional EDUTEC 2012: Canarias en tres continentes digitales: educación, TIC y NET-Coaching. Canarias, 2012. Disponível em: $<$ https://www.researchgate.net/publication/258167462_Redes_sociales_en_el_aula_y_su_utilizacion_en_e 1_contexto_universitario $>$. Acesso em: 06 fev.2016.

Hall, Stuart. A identidade cultural na pós-modernidade. Rio de Janeiro: DP\&A, 2005.

Herring, Susan. Computer-Mediated Discourse Analysis: An Approach to Researching Online Behavior. In: BARAB, S. A., KLING, R., GRAY, J. H. (org.). Designing for Virtual

Communities in the Service of Learning (pp. 1-35). New York: Cambridge University Press, 2004. Disponível em: <http://ella.slis.indiana.edu/ herring/cmda.pdf>. Acesso em: 29 fev 2016.

Marlangeon, Kaul de. Unidades extralingüísticas de Análisis del Discurso de (des)cortesía. In: Dossier El estudio de la cortesía y la descortesía. Signo y Seña, numero 26,Buenos Aires: 2014. Facultad de Filosofia y Letras (UBA). Disponível em: < http://revistas.filo.uba.ar/index.php/sys/index> pp. 9 - 24.

Mercosul Educacional. Sistema de Informação e Comunicação - SIC. O setor educativo do Mercosul (SEM). [S.1.], 2016. Disponível em: < http://edu.mercosur.int/pt-BR/mercosul-educacional/o-que-e.html >. Acesso em: 01 fev. 2016. 